
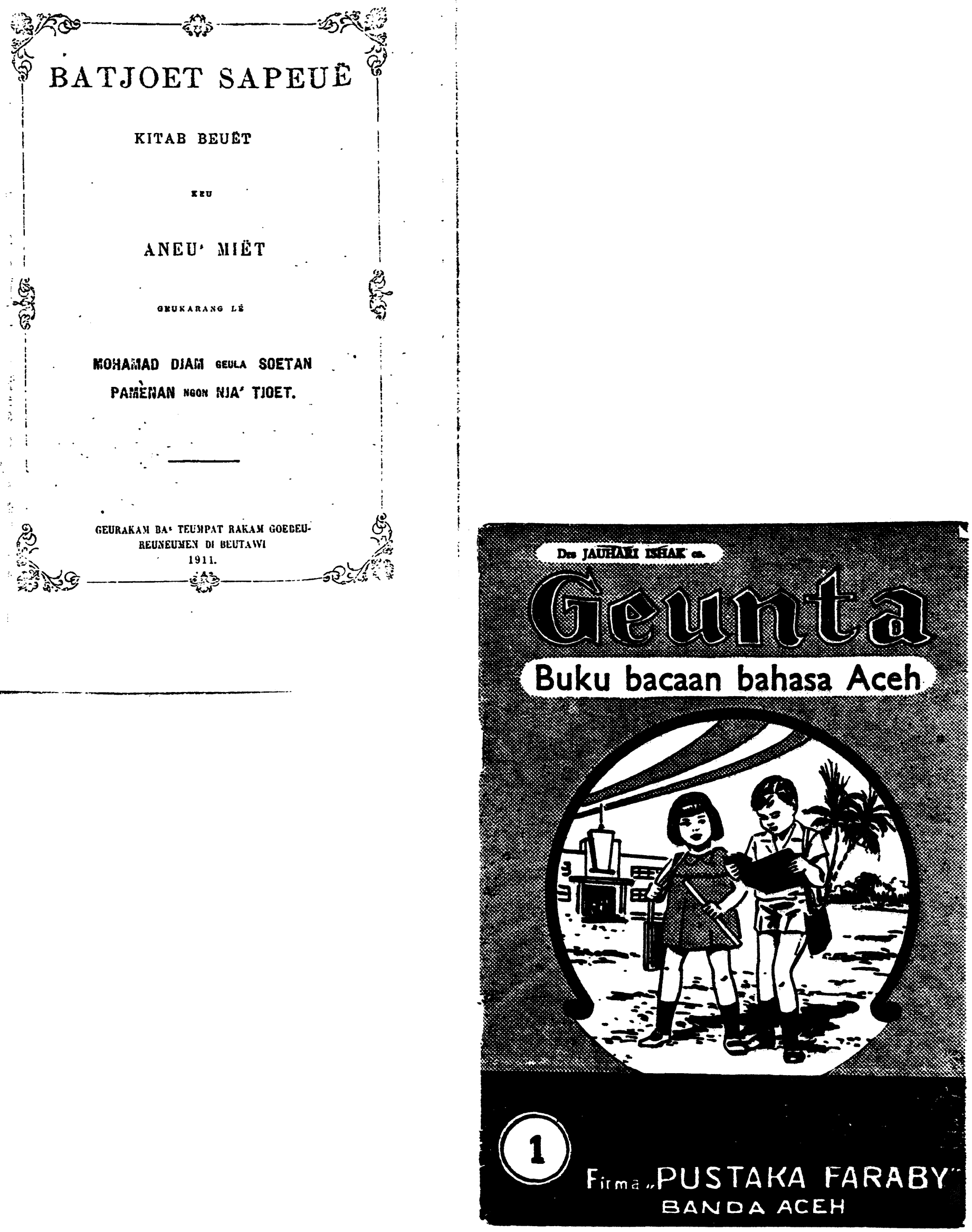


\title{
EYEGLASSES: SOME REMARKS ON ACEHNESE SCHOOL BOOKS
}

\author{
Saya Shiraishi
}

In the course of studying Acehnese I have come across two textbooks designed for teaching young Acehnese children to read at school. The following remarks were originally made as my own mnemonic device in remembering what 1 , as a novice to this language, had read in them. ${ }^{1}$

Let me start with a brief description of these textbooks.

"A Bit of Everything: A Children's Reader [Batjoet Sapeuë: Kitab Beuët keu Aneu'Miët]" ${ }^{2}$ was published by the Government Publishing House in Batavia in 1911. It also has a Dutch subtitle, "Leesboek voor Atjehsche kinderen," inside the cover. The book was intended to be read as the third Acehnese reading textbook at elementary-level schools in Aceh under Dutch colonial rule. The thirty-seven-page book consists of fifty-six numbered sections with entries such as: 1. New book; 2. Reading; 3. School.

"Reverberation [Geunta]" ${ }^{3}$ is the title of a series of Acehnese reading textbooks prepared by the Department of Elementary Education and Culture of the Special District of Aceh in 1968. They also carry an Indonesian subtitle, "Buku bacaan bahasa Aceh untuk Sekolah Dasar," on their front covers. It is as if the Acehnese Geunta is encased in the Indonesian title, whereas Batjoet Sapeuë is a garment worn by the Dutch. There are six textbooks in the Geunta series, each consisting of about forty-five to sixty-five pages. To Geunta One, Geunta Two, and a part of Geunta Three are allotted the description of the daily life of school children in contemporary Aceh. All books in the Geunta series also have pictures in each of the chapters.

The distinctive feature of Batjoet Sapeuë appears in its first section. The translation of the section is as follows.

\section{New book}

Book Two [whose title is] Silajeuë I have already finished reading, therefore I read this book. Various accounts are contained inside the book. I am pleased to meet with this book. The teacher said that it is my duty to be careful not to waste nor split the book. Therefore I wrap the book in thick

1. I would here like to thank Professor James Siegel for teaching me Acehnese and for his guidance in translating these textbooks. I am, of course, responsible for the views expressed in this article, as well as any errors in translation or interpretation.

2. Mohamad Djam geula Soetan Pamènan ngon Nja' Tjoet, Batjoet Sapeuë: Kitab Beuët keu Aneu' Miët (Batavia: Teumpat Rakam Goebeureuneumen, 1911).

3. Drs. Jauhari Ishak, Khalid Ibrahim Abu Hani, Geunta: Kitab Beuet Basa Acèh (Banda Acèh: Pustaka Faraby, 1974). 
paper. I read this book twice and three times repeatedly, I am pleased to know all the contents [haba] of the book.

My friend who has already read this book said that there are many stories inside that make him happy.

It is obvious in this context of the section that "new book" or "this book" indicates Batjoet Sapeuë itself. Who is the speaker "I," then? Throughout the textbook there is no effort to establish the identity of "I." We may well, therefore, assume that the reader of this textbook, presumably a young Acehnese child, is expected to identify himself (the contents of the book suggest that the readers are more likely boys than girls) with the speaker of the textbook. What happens, then? The reader finds in the book the description of what he himself is doing at this moment, that is, opening the new book. It is as if the reader sees his own image reflected in the book. The speaker of the book says, "I read this book twice and three times repeatedly, I am pleased to know all the contents of the book." In other words, the reader studies his own image two and three times, or the reader looks into himself closely and detachedly. The pleasure of knowing all the contents of one's self will emerge from the pages of the book.

What is this "reading"? Reading this textbook is, in this context, equivalent to looking into oneself to know who one is. What is the process of this "reading"? What is the process of knowing oneself through the reading of Batioet Sapeue, which means "a bit of everything," or "what everything is about"? The second topic of the book is "Reading." Here is a translation of the second section.

\section{Reading}

At the time when I was not yet attending school, I was terribly amazed to observe people read letters [soe-rat]. It was beyond my comprehension that scratches could become words. But since attending school I have come to know each letter [ha-raih] has its own name. The letters which are arranged in a certain sequence form a word. Two or three of these words become a story when they are put in a certain order. I remember the case I heard of before, the story of a stupid man who bought a pair of eyeglasses. In the mind of the man, because of the eyeglasses he would become able to read. Because he had seen the Tabib using his eyeglasses while reading letters.

According to this section, one learns how to read by attending school. And "reading" here is limited within the confines of the silent activity of reading with one's eyes and excludes reading by recitation. Because "I" was amazed at "observing" people read letters, not listening to people read letters. Therefore, even though the reader of this textbook must have already acquired fluency in speaking Acehnese through his daily experience of speaking and hearing, that has nothing to do with his ability to read books. He has to learn that there are letters which constitute words. He has to know the names of these letters, and the way in which the letters are arranged to form a word. And further, he has to learn how the words are put to become a story.

Reading is anything but making a direct correspondence between speech, which the reader already knows, and scratches, which he is to learn. Previously, when one did not think of reading the language, the words may have been like fruits on the trees. One may merely pick any one of the fruits, or words, in speech, whose taste one already knew through one's experience. Now in reading one has to cut the fruit into pieces to know what constitutes the fruit before one may enjoy its taste, if one ever will. This is well demonstrated in the layout of the textbook. Each word of the book is printed syllable by syllable, which usually diverts the 
reader's attention from the meaning of the word. One never learns the elements of a fruit by tasting it. One never learns how to read from one's daily experience. The experience only leads one to think that it is the eyeglasses that perform the magic. The eyeglasses are the converter of the scratches into speech. Yet ability to read does not come from the eyeglasses, does not come out of the reader's experience in everyday life.

Here, at this point, the reader becomes vulnerable. Because what he knows through his own experience is declared to be as useless as reading with eyeglasses without knowing how to read. As a source of knowledge daily experience should be discarded. Only schooling makes one read. This applies to the entire field of knowledge. Let us examine another example concerning the kind of knowledge the textbook presents to the reader.

\section{Pots and Pans}

A pot is a vessel in which we cook rice; a pan is a vessel in which we cook vegetable soup. A vessel for frying is called a frying pan. We make pots and pans from clay. Have you ever seen people making pots and pans?

The clay which is already kneaded is shaped into a pot, then fired, and finally it becomes usable.

The Europeans forge pots and pans from iron or tin. That's the good way. They last long and are hard to break. Iron pans can be used for years. And so can iron pots.

Tamils like pots and pans made of copper. But the copper pots are not clean when they rust. Copper rust is poisonous.

Pots and pans are things quite familiar to young children. They see their mothers and sisters cook food in the pots and pans in the kitchens almost every day. They may well know how to handle the pots and pans while cooking, and how to wash and dry them, and where to store them. Yet this is not the kind of knowledge the textbook regards as worthy to know about. The knowledge that is worth reading about consists of what pots and pans are made of and how. As one has to know the names of letters in order to read, one has to know the names of various materials of which the pots and pans are made. If one does not have knowledge of them, the book warns the reader, one can be poisoned by them.

What the reader previously came to know through his own daily experience is written off and discarded. He does not know anything any more. What he knows now is: "I do not know anything any more. I am the one who knows nothing." Because he does not know anything any more it becomes even more necessary for him to read the book which shows the reader what everything is about. Only the textbook enables him to know the nature of things as well as how to read.

The next example shows us the way the textbook presents this "new" knowledge.

\section{Clothes}

Jackets, trousers, loincloths, headcloths, hats are all clothes.

If we were to go out on the main street without clothes, we would be laughed at by people, who would say that we do not know adat. It thus makes it our duty to wear clothes. We are very careful to put clothes on our body, not to spoil them, and to keep them clean always. Rich people wear expensive clothes. But such expensive clothes become useless if they are not clean.

Let us wear inexpensive clothes provided they are clean; that is the right thing to do. As for me, I would prefer to wear inexpensive, clean, cotton clothes to rotten-smelling, unclean, silk clothes. Women enjoy 
adorning themselves with gold and silver. For us men, it is not common to put on these adornments.

One of the most familiar items of everyday life, clothes, is the topic of this section. Clothes are divided into different categories in the first place: jackets; trousers; loincloths; headcloths and hats. As in the case of the words in reading, this classification of divide-and-name is the mental exercise of objectifying clothes. Clothes have been an indispensable part of oneself in one's daily life. It is difficult for one even to feel that one's body is wrapped in something alien to one's body. Now, imagine yourself taking off each piece of your clothes, in order to classify them into the separate categories stated above: jacket; trousers; loincloths; headcloths; etc. At the end of the classification you would be left naked. Through this objectification one is now able to see that clothes are not a part of oneself, not the outer skin of one's body. One can still breathe, walk around, and be oneself without putting any clothes on. Therefore it is not impossible for one to go out in the streets naked. If so, why do people not go out naked? The textbook then tells the reader why. Because a naked man on a street is inappropriate. He would be laughed at and blamed for his ignorance of adat. A man puts on clothes to go out to the streets, not because clothes are part of his skin that cannot be taken off, but because that is the appropriate way of human life which he is obliged to respect.

For the same reason the reader has to keep his clothes clean. If he does not keep them clean, they begin to have a rotten smell, the smell of his own body. Clothes become as a part of his own body again. Walking on the streets with his smelly clothes is, therefore, like walking on the streets naked, neglecting his obligation. Even expensive clothes become "useless."

Clothing is an artificial human effort, and the appropriate mode and arrangements are fixed and judged in the name of adat. We will come back to the question of "people" who watch over our naked man on the streets later. Meanwhile, we shall go on studying the process of making the reader of the textbook a knowledgeable youth. So far it has deprived him of his cherished experience, family life, and his clothes. It does not stop here yet.

\section{Eyes}

Eyes are quite useful for us. With eyes we see things. A blind man is terribly unfortunate; he can only hear things, does not have the sight of anything. Those people who are very old have failing sight, but there are young people who are exposed to eye disease and become blind. Therefore it is a very good thing to take care of the eyes in order not to become blind. Once one becomes blind, no medication is possible. When getting out of bed one ought to wash one's face and get rid of the sand.

Swollen eyes should be immediately treated with medicine. In case any dirt gets into the eyes, do not rub the eyes. There is nothing we can do once we become blind. There are some people whose eyes are blind on just one side, and there are those whose eyeballs are white, and those [whose eyeballs are] shining. These people are terribly unfortunate; being never able to see the world, they cannot distinguish even their mothers and fathers.

The eyes are genuinely parts of one's body, unlike clothes that can be physically taken off from the body. One sees things without thinking of the eyes with which one perceives the objects. When one observes people performing their daily activities, when one reads books, and when one looks into a mirror, eyesight is always there taken for granted. Now in this section, however, the reader sees himself saying "Our eyes are quite useful for us. With eyes we see things," as if he is talking about something, some kind of useful tool. The reader is invited to 
measure his own eyes with his mind's eyes. Tools are quite useful for a man to accomplish his work with. Yet no matter how useful they may be, any tools must be expected to become unworkable someday. Any tool can be lost, mistreated, or simply worn out eventually. So it is with eyes. There are some people who have lost their eyesight, whose eyes have been damaged, whose eyes fail to function properly, whose eyes are disfigured, or whose eyes are already time-worn. Once lost, they cannot be recovered again.

By now it seems to be a great miracle that our eyes are still functioning. I myself have felt the urge to look in a mirror to see and examine my eyes. One could even feel that eyes are put on, as with wearing eyeglasses for the first time.

Thus the eyes are also detached and objectified. Now the reader is taught to treat them in the same manner in which he treats his clothes. He has to wash them and keep them clean. Otherwise, the book kindly reminds him of the possibility of his losing sight of the world and of his mother and father.

When a young child learns how to read, according to Batjoet Sapeuë, he has to know the names of the letters, and how the letters and the words are arranged to form a coherent story. He also learns the nature of things by examining what they are made of and how they are arranged and related to one another. The law that governs the arrangements and relations of daily human activities in Aceh is called adat. It is in this respect that the textbook asserts only schooling is capable of providing the children with the knowledge of adat.

\section{School}

The school house is built to be the place where young children study. At school we study various sciences. We read, we write, and we count. Other than that they also teach us adat, appropriate manners. Many young children who do not go to school do not know adat. They are bad natured.

People always dislike children who are untutored. Mother and Father are very happy if their children are educated and, moreover, good natured.

The famous figures of present times all have previously studied at school.

The things one never learns through one's own daily and personal experiences one learns at school. The child learns various sciences, and reads, writes, and counts. He is also taught adat. He will become "educated" by going through this process and will not think that eyeglasses make him able to read. And his knowledge and respect for adat form a good-natured child. This makes his mother and father happy. He may have a very good chance of becoming famous. If, on the contrary, the child does not attend school regularly, he is considered to be bad natured and disliked by people. That is the pronouncement of the textbook in this section.

Now it is time for us to deal with the question of "people." The word for "people" in the textbook is "gob."

\section{4. [Child's] Nature}

The duty of young children lies in a good nature. Any conduct by young children that is praised by their parents is good. Anything that is criticized is bad. Bad nature invites wickedness. If we are not good natured, not loved by people, people get angry with us. Moreover, Mother and Father, relatives and friends, are embarrassed in front of people. Therefore, do not develop a bad nature.

Who are "gob"? Or what does the word "gob" refer to? The "gob" dislike those children who are bad natured. The bad-natured children are those who do not 
know adat. The "gob" also laugh at the naked man on a street and blame him for not knowing adat. It is the "gob" who protect adat from the bad-natured child who is to become a naked man on the street. There is no mention of the late sultans of Aceh in relation to adat, even though the source of Aceh's adat has always been identified with the great sultans of the past.

Now, according to the textbook, it is the "gob" who watch the children perform their daily activities and who judge whether their manner of conduct is in accord with adat. At this stage the reader sees in the textbook not only his own image but also the existence of the "gob" who watch over what his image is doing from the corner of the pages as a scornful audience. This corner gives the reader a second perspective. He can not only see his image in the book, but can also see what the "gob" see there. It is like getting a second mirror in which he finds the image of himself which is perceived by the others, in this case the "gob."

Yet the "gob" are not his parents, relatives, nor his friends. The word's literal meanings include the notion of strangers as well as people in general. Therefore the reader also has a third viewpoint. The viewpoint of his parents, relatives, and friends. At first sight, the reader sees himself reading at school or classifying his clothes. At second sight, he sees the "gob" watching what his image is doing and forming a judgment on him. And he sees his image knows this. Because it is the "gob" that obliges his image not to walk on the street naked. And third, the reader sees his parents watching this intercourse, and feeling either happy or ashamed in response to what the "gob" think of their son. And their son, the reader's image in the book, knows this also, and finds it to be another compelling force. Moreover, the image knows that the "gob" also know his parents' anxiety and make use of it as a means of influencing him to observe adat. In this triangular interpenetrating situation of his image, the "gob," and his parents, the reader sees the arrangement of adat itself which, in turn, rules the arrangements of daily activities. It is this arrangement of adat that obliges him to respect adat. He is now able to divide-and-name the whole arrangement of adat. Now adat is there, objectified and detached from the glory of Aceh. The young child learns how to read while discarding his own experience, and he now learns adat while discarding its sanctified source.

The textbook's betrayal of adat, that is teaching adat by unwrapping its arrangement, does not end at this point.

\section{Flower}

The oil of pleasing scents is distilled from flowers. There are various names for flowers: boe-ngong meu-loe, boe-ngong seu-manga, boe-ngong djeum-pa. Women are touched by flowers deeply, and there are those who use flowers as adornment of their hair, and there are those who stick flowers behind their ears.

Some women place flowers between pleated cloth to enjoy the fragrance. European ladies make strings of various flowers or arrange them to give them as presents to their friends. This performance is in accord with adat.

There is no such thing as flower. Flower exists only as a word. We experience flowers not as flower but as an individual flower which may happen to be named meuloe or seumanga. Each one of the flowers which we encounter in daily life is distinct from every other. Even those flowers which share the same name come into contact with us uniquely, as a young bud, or in its full bloom, under the daylight, or in the evening. The interjection that may arise in these moments of encounter with such beautiful objects is not the subject of this section. All such individual experiences are cast away. Like the clothes and the writings which have 
already been mentioned, the flower is divided into separate names, such as seumanga or djeumpa. In the second place the book makes the reader conceive how each of them is arranged and utilized in the artificial sphere of human life in Aceh. Here flowers are associated with women as ornaments that adorn them. Flowers should be placed on women's hair, behind their ears, and in the folds of their clothes. Flowers are converted into jewels, which are an element of clothing. The flower which is a product of nature is taken prisoner by adat.

However, there is no inherent reason why flowers should become adornment for women. The reader is expected to assume that the flowers are capable of becoming something else. In Europe, the textbook offers another alternative, the ladies arrange flowers in a way that converts flowers into presents which express friendship among them. This performance is also in accord with adat.

Obviously the adat which makes flowers a sign of friendship is a different adat from that which makes flowers an element of clothes. Flowers are arranged according to a different adat. So, if the adat is different, flowers must be divided into names different from those of Aceh to begin with. There is their adat in Europe, as well as our adat in Aceh. The same theory applies to clothing. If clothing is an act of making cloth into clothes, there should be more than one way of classifying and arranging clothes. Our way of donning appropriate clothing is not the only possible way of putting pieces of cloth on our bodies. Different kinds of appropriateness can be found. There is nothing sacred about this. As the clothes can be physically taken off from the body and be replaced by another kind of clothes, which are differently divided, named, and arranged, our adat can also be taken off and be replaced by another adat.

The reader who stands outside the triangular arrangement of adat enforcement is allowed to perceive this all. The young child now stands not only outside this arrangement but above them all, above his image, above the "gob," above his parents, because only he can see them all. Only he can read the textbook which unwraps the sacred character of adat.

There is yet another thing that places him above them all. That is science, which he also learns at school. Let us examine the sections which treat scientific topics.

22. The moon

Moonlight is less bright than sunlight. One can look straight at the moon. On the 14 th day the moon is full, completely round like a coin. At the beginning or end of the month it is bent like wings. Sometimes there is a half moon. Certainly we never wondered why such a thing happens. Yet in the long run there is a reason why the form of the moon changes. Man's science of the sun, the stars, and the moon is great. Quite amazing science is.

\section{Earthquake}

An earthquake has just come over us. My house sways back and forth. I am alarmed and I stumble. My mother brings us, all my brothers and sisters, down outside. My father is not at home at the time, he has gone fishing. I am stupefied. What causes this to shake the land back and forth?

The "gob" say that there is a cow underneath the world. The cow shakes up the land. But the teacher of my school tells us the story is hot air. The teacher promises when we go through higher grades, we will be able to understand this wondrous fact. 
These mysterious occurrences which are beyond the young reader's comprehension make him feel stupefied (hireuën), and uneasy. The "gob" give him an explanation which attributes the cause of the earthquake to the shake of the great cow's body. This explanation equates the "gob" with the stupid man who bought eyeglasses in order to convert scratches into speech.

In the section on "Reading," the reader who was a young preschooler was terribly amazed (hireuën), at observing people (oereuëng, not gob) read letters.

Since attending school he has come to know that each one of the letters has its own name, and when some of them are arranged in a certain way they form a word and eventually a story. That is the process he has come to know how to read. Science will place all mysteries under control in precisely the same manner. When a child faces a mysterious happening and feels stupefied and uneasy, what he has to do is to wait until he learns about it at school. He may well prepare a box in his mind labeled "questions" in which to store all the mysteries, instead of looking for the answers at false corners. If he believes that school is the only church at which he learns the truth of mystery, the mysteries stored in the box will not bother him any more.

Once this belief in schooling is established, the future of the school as the institution of learning is assured. The textbook tells the reader that he knows nothing. It also tells him that those without schooling are stupid. So both of them are stupid. But there is one difference. The reader who knows that he knows nothing knows that he is stupid, while those without schooling do not. Then the textbook promises him to teach everything when he goes through the higher grades. But the teachings at school never satisfy all the questions he has. Therefore the students, who have become aware of their ignorance and stupidity, are more vulnerable to the promise of knowledge offered by schooling. The more he learns at school, the less he becomes knowledgeable. What he knows now is that he knows nothing. He has to cling on to school in order to keep his hope that he will someday know what everything is.

Geunta, or reverberation, is the title which is assigned to the new series of Acehnese reading textbooks composed in 1968. A number of affairs of historical importance have occurred since the previous textbook, Batjoet Sapeuë, was printed under Dutch colonial rule. The Japanese Occupation during World War II, the social revolution in Aceh, and Indonesian independence. The rebellion of Daud Beureueh and the 1965 affair. Now schoolchildren learn the Indonesian language as well as Acehnese. The future of Acehnese seems quite uncertain.

Let us begin with the first chapter of Geunta One, where the speaker is now a girl, Si Ati.

\section{Going to school}

The roosters crow, the day breaks.

The drums of meunasah ${ }^{4}$ are already beaten.

We all rise.

After washing, we pray together.

Today is the first day of school.

The first day to attend Class Two.

I serve cooked rice on the table.

4. A village meeting house. 
Then we eat our morning rice [boe beungoh ${ }^{5}$ together.

We have to eat our morning rice.

If not, we/you [geutanyoe] get sick.

We put clean white shirts on.

Then we take our bookbags.

In the bags there are various things.

Reading books, drawing books, notebooks, pencils, all together.

This year my brother Si Wahab enters school.

Si Wahab goes along with us to school.

When it is the time to go we ask permission of our mother and father.

Then we say "assalamu alaikum."

Alaikum salam beuseulamat nibak baya

(Peace be unto you, may you be spared from misfortune).

This is the beginning of Geunta and the beginning of the day. The beginning of Geunta, reverberation, is the rooster's crow, and the beginning of the day is the sunrise. The rooster's crow rebounds at the meunasah as the drum beat and the sunrise is responded to with "we all rise." Finally, in total response to these reverberating calls, "we pray together." We voice the sunrise prayer together. While the morning air is filled with the reverberation of the sound of the sunrise prayer and the first rays of the rising sun, the mind registers its reflections. "Today is the first day of school. The first day to attend Class Two."

The rhythm continues: "I serve cooked rice," and all the family eat the morning rice together.

A call and the response from all, accompanied with the reflection: "We have to eat our morning rice. If not, we get sick."

This reflection is also the recollection of what has been registered in one's mind before, probably as a result of hearing the sound "boe-beungoh." Because at this point the word "kamoe" which refers to "we (I and they)" is replaced by "geutanyoe" which refers to "we ( 1 and you)." We may assume that the words were originally spoken by the parents or by the teacher, and registered in the mind of "I." The "boe beungoh" stimulated the recollection of these words, which reemerged in the same form they had been registered. The word "geutanyoe," when compared to "kamoe," places stress upon "you" at the expense of "I." Therefore the original words could be "you have to eat boe beungoh. If not, you get sick."

Now the children prepare to go to school. They put on clean white shirts. And then the children take their bookbags. At this moment the bookbag (tah buku) reminds the speaker of the textbook of another set of recollections. "In the bags there are various things. Reading books, drawing books, notebooks, pencils, all together." This list of names is different from the Batjoet Sapeuë's divide-andname lists, because the bookbag is not disassembled to be examined.

Now the time has come for the children to ask permission and say, "assalamu alaikum" to their parents. The parents return the blessings, alaikum salam beuseulamat nibak baya. Yet the response is not placed in quotation marks here, in contrast to the children's initial blessings. And no recollection follows this exchange of blessings. Did the children not wait for their parents to finish their blessings

5. Since there is no standardized spelling of Acehnese, throughout this article I have followed the orthography of Hoesein Djajadiningrat in his dictionary of Acehnese (R. A. Dr. Hoesein Djajadiningrat, Atjehsch-Nederlandsch woordenboek [Batavia : Landsdrukkerij, 1934]). 
and see what the blessings recall in their mind? The answer, it seems to me, is that the blessings caught by the children's ears and the recollections revived in the children's mind merged into each other and effaced the distinction between the two. Because the two were completely identical. As a result, the return blessings, alaikum salam, could no longer be attributed solely to the parents. The children's mind also said that blessing. Therefore no quotation marks.

How does such a thing happen? We will seek and find the answer in Geunta.

From the very beginning it seems thus clear that the Geunta series has distinctive features from its predecessor, Batjoet Sapeuë. Some comparisons of the two textbooks may well help us start to establish these features. There is a story in Geunta Three which serves our purpose well.

Geunta Three is supposed to be the equivalent of Batjoet Sapeuë, for both books are intended to be read as the third reading textbooks for young Acehnese children. Some of the contents of Geunta Three are obviously remolded from the materials found in Batjoet Sapeuë. The most interesting comparison may be made between the first chapters of the two textbooks. The first section of Batjoet Sapeuë was "New book"; the first chapter of Geunta Three is as follows.

\section{Class three}

We are now in class three.

We have already finished reading kitab Geunta $T$ wo.

Then now we have come to kitab Geunta Three.

In class one we studied a writing-reading book.

In class two [we used] kitab Geunta One and kitab Geunta Two.

Now [we use] kitab Geunta Three. Because we are already in class three.

According to the teacher's words, class four [uses] kitab Geunta Four. Class five, kitab Geunta Five. Class six, kitab Geunta Six.

In all these books there are many fine stories. Then there are also, pictures which are very good.

They shall become the models for all of us.

Therefore the teacher tells us to guard [the book] on the alert. In order not to tear the book. He tells us to wrap the book so it won't get dirty.

[We are] very happy in our hearts, when we see kitab Geunta Three. The book shall absorb us with the stories which are good.

The basic plot of this chapter is almost identical with the beginning section of Batjoet Sapeuë. However, a striking alteration is made in the concluding sentences. "[We are] very happy in our hearts, when we see kitab Geunta Three. The book shall absorb us with the stories which are good." The pleasure of meeting the new textbook is expressed as the pleasure of anticipating the pleasure of being absorbed in stories from the book. Whereas, in Batjoet Sapeuë the pleasure is directed at "knowing [toepeuë]" the contents of the book. Indeed, we have discussed the pleasant process of "knowing" things in previous pages. What is, then, the pleasure of anticipating the pleasure of being absorbed in the stories of the book? We must also try to figure to ourselves what it is like to be absorbed with Geunta, the final goal of reading this textbook.

The word employed here for "absorb us" is "peulalè kamöë." Its literal meaning is making oneself negligent and inattentive. "Yet "making oneself absorbed"

6. Djajadiningrat, Atjehsch-Nederlandsch woordenboek. 
seems to be the better way of translating the meaning in this context. ${ }^{7}$ The word "absorbed," however, means being occupied with one's whole attention. How can a word be used for both "inattentive" and "occupying his whole attention"? We will examine the usages of the word in the context of Geunta.

The next two chapters in Geunta One carry the titles "peulalè adòe (1)" and "peulalè adòe (2)." The title can be translated in these cases as "lulling babysister." These two chapters show us how the baby is lulled, that is, how the baby is put into the state of "lalè."

$$
\text { Lulling baby-sister (1) }
$$

After the noon prayer Mother and Father have already gone to the garden. Sister Fatimah and Brother Isa also have gone to help Mother and Father. In the garden they plant peanuts.

And there are some more plants, a few of each kind.

I and Brother Ali stay at home.

I am told to lull the youngest [sister].

The youngest cannot walk yet.

She can just stand.

When she stands she holds on to the wall.

Her wail is very sharp.

Her wail pervades the whole house.

Sometimes she cries.

When she cries I carry her downstairs.

I put her to sleep by lulling.

I give her anything at all to pacify her.

I am now tired too.

The youngest does not ever become quiet when she cries.

Then I give her sweet drinks and bananas.

$$
\text { Lulling baby-sister (2) }
$$

When she becomes quiet I lay her in the cradle.

To put her to sleep promptly I swing [the cradle].

Then I sing the lullaby I learned at school and after that I add some more.

The passage is followed by a set of lullabies.

In the first chapter their house is pervaded with the baby's sharp wailing voice. The baby is obviously tired and disturbed; that makes Si Ati (the speaker "I" of Geunta) tired and disturbed also. The baby needs to be put into the state of "lalè."

In the second chapter, the baby is already quieted. She is now filled up. The comforting feeling of being swung in the cradle and listening to her sister's lullaby is the state of being "lalè" as much as the means to be put into that state. The disturbing sharp voice is replaced by the soothing singing voice, which is accompanied with the rhythm of the swing of the body in the cradle.

The negative form of the word "lalè" is used in the following context of the last chapter of Geunta One.

\section{Prize}

The book Geunta One is almost finished.

The teacher tests to see who is fluent in reading.

7. James Siegel, Shadow and Sound (Chicago: University of Chicago Press, 1979), p. $71, \mathrm{n} .113$. 
He tests all the students of Class two.

We are told to read one by one.

We read Geunta One.

Which he tests from the beginning to the end.

Because of this we repeat [reading] earnestly [sunggoh] at home.

Si Ati concentrates her attention [hana lalè] [upon reading] day and night.

She repeats countlessly and earnestly.

At the test, there are some [students] who are not yet fluent enough.

Then three are chosen as the most accomplished students.

One girl, two boys.

The girl is Si Ati.

Si Ati is chosen as the most accomplished student.

Si Ati is rewarded with the prize of one dozen [note]books and pencils.

The second winner, one dozen [note]books and six pencils.

The third winner, one dozen [note]books and three pencils.

Those who are chosen as the most accomplished students are very happy.

-.

Si Ati, the model student of Geunta, reads the textbook for the purpose of achieving fluency in chanting it. For that purpose she practices chanting the textbook with countless repetitions. In so doing she has to keep her attention on what she is doing, without being distracted. This is expressed with the words "hana lalè," being not inattentive, or concentrating her attention. What makes her able to concentrate her attention on reading the same texts with countless repetition? Her earnest will, "sunggoh." It is her earnest will that enables her to keep her attention concentrated (hana lalè) throughout the repetition.

The final accomplishment of learning the textbook at school is fluency in reading the book. Fluency is achieved only by countless repetition. One needs to have a strong and determined will actually to carry out the repetition. When one is determined and earnest, one is capable of concentrating one's attention upon the texts which one has to read.

The theme that the students acquire fluency by repetition appears many times in Geunta and sets the basic mode of learning. The next chapter is another example of this.

\section{Back from School}

Today is Monday.

The first day of school this week.

In the morning, the arithmetic lesson.

After that, writing and reading.

Lastly singing.

The song is [lullaby] do ida idi.

At first the teacher sings: do ida idi

- . -

After that we sing in the intervals between the lines [of the teacher's song]

Then henceforth all together at the same time.

Sometimes then it is the girls' turn to sing by themselves.

The same with the boys.

Lastly we are told [to sing] one by one.

The girls or the boys who are fluent sing.

The song is very good and vibrant.

Very fluent the way the teacher teaches us.

We all rejoice immeasurably. 
In learning a song, as in learning to read, the students must repeat after their teacher line by line. At this stage, the students' voices are more likely a noise than a song. Practicing by repetition continues. At the end, when the students are required to sing one by one, they have whole lines inscribed in their mind. When she sings alone the inscribed voice helps her to sing it out. Finally, all the students who thus become fluent sing the song together. Now the friends' singing voices join in the intercourse of her voice and mind. The voices her ears are listening to correspond with the voice her mind is listening to. All the voices now resonate in her body between her ears and mind, and assure her and assist her to sing the song even louder. The louder she sings, she knows, the stronger her voice resonates with her friends' voices and minds also. "The song is very good and vibrant." The teacher's fluency is answered by the fluency of her students. The classroom is filled with the reverberation of their singing voices and their singing minds. "We all rejoice immeasurably." The pleasure produced among the participants is the pleasure of feeling the reverberation of both the sounds and minds in which one's own voice and mind are shared with all the others. It is to this end that the students keep repeating the song.

In order to become a resonator herself, she has to control both her voice and mind. At the beginning of this process she is required to have an earnest will. Her "sunggoh"-ness prepares her mind to become a pure white sheet of paper. During the repetition, her condition of being "hana lalè" is the condition in which her mind is placed under the strict control of her earnest will. She inscribes the verses of the song in her mind by repeating them, as she tunes her voice up.

Once this process is completed, it is not necessary for her to be fully attentive any more. The right sound comes out of her mouth well tuned all by itself. Simultaneously her mind prints out the lines in the right voices at the right moment. This frees her from any of the assiduousness required during repetition, and makes her leap into the pleasure of surrendering herself to the sweetness of reverberating sounds in her body. At this stage she need not place her mind under the strict control of her will any more. Her will is now allowed to be negligent in controlling her mind. Rather, she is controlled and fully occupied by her singing mind. Yet her mind is itself already premeditated and so programmed that what results from the command of her mind is well-studied spontaneity. She is in the state of "lalè."

She is now in a state equivalent to that of the baby who is lulled in her cradle. The sister's singing voice and the rhythm with which her cradle is rocked are, for the baby, all familiar to her senses. The song, the singing voice, and the rhythm are all repetitions of what the baby has experienced the day before, and the day before the day before. They all have been imprinted in her mind, and perceiving them all over again assures her. Her mind works as a sounding board for what she is listening to, the reverberation of which occupies and fills up her body. The baby girl may not voice the verses of lullaby which appear in her mind now, but when the time comes for her to sing a lullaby for her younger sister, or for her own baby, she will be ready for singing because her mind will have been prepared to print out the song she is listening to at this moment in her own cradle. This is precisely the reason why her sister, Si Ati, is not only singing the lullaby she has learned at school, but adding more song spontaneously.

At this moment, by the side of the baby's cradle, we can hear only Si Ati's soft voice. The case is different for Si Ati. Her mind's ears are hearing the singing voice she listened to when she was a baby in that cradle, and her mind's ears may also be hearing the singing voice her baby sister will sing in the very spot by the side of their house's baby cradle. (Since residence is uxorilocal in Aceh, women tend to raise their children in the house they grew up in.) She feels the 
reverberation in which her voice and mind are shared with all the others, those of the past and those of the future. All the others who share this lullaby of Aceh.

Geunta tells the young Acehnese children that there is more to be shared with each other. The outstanding feature of Geunta is the description of the daily life of the children. Let us read the following two chapters.

\section{Lunch}

The time is the middle of the day.

Mother is cooking.

Si Ati and Si Ali are back from school.

Sister [Si Fatimah] and Brother [Si Isa] are not back yet.

At noon they will be back.

Si Ati and Si Ali help Mother.

Si Ati helps her cook.

Si Ali washes plates.

When it is ready Si Ati brings the meal.

Then she serves it at the table.

In a minute, Sister and Brother too are back home.

Following that, Father too is back.

After the noon prayer we shall eat lunch together.

The meal time begins with bismillahi rrahmani rrahimi.

We all utter bismi Ilah; no one chats.

After the meal we all utter alhamdu li llahi.

After lunch the sister and brother of Si Ati clear the table.

The plates, the glasses, the saucers are washed by Si Fatimah.

Then Si Isa dries them.

Father and Mother go to the garden.

We stay home to lull our baby sister.

\section{Sunset prayer}

The day is already evening.

All the family have already finished washing.

The day is already close to sunset.

All the animals are already back.

Si Ati gives food to roosters.

Si Isa gives food to ducks.

Si Ali gives food to goats.

After eating food the animals lie down.

The sun too has already gone down.

The pens of the animals are closed up by the children.

Not long after that the drums too are beaten.

The mark of the time of sunset.

Then all the family get ready to pray.

Si Isa performs the first call for prayer.

Then the second call.

Then the sunset prayer is performed with a leader.

Father becomes the leader of the service [imeum].

All the others perform the service.

After the prayer we eat the meal.

Then go to chant at the Teungku's.

The chanting place is not far away.

All the young gampong children read there.

Some study alif ba [Arab alphabet],

Some study iuama. 
Some read the Koran.

After reading Teungku tells us a story.

The story is a model.

After that all perform the evening prayer.

Then later go back to our own houses one by one.

All the young children utter:

Assalamu alaikum warah matullahi wabarakatuh

Then blessed by Teungku with:

Alaikum salam warah matullahi wabarakatuh.

We are now able to reconstruct the daily activities of Si Ati and her family. Yet this innocent outline of the day of a girl's life is not presented here as a highly unique and personal one. Si Ati will be doing almost the same thing the next day and the day after, as she did the day before. As she repeats reading the textbook countless times, she repeats her routine day after day. So does each one of the members of her family. Though they all have their own distinct daily routines, at certain times of a day their routines intersect and form a particular rhythm of family life. At noon all the family members are back from school or from work, and they pray together and eat lunch together, and they disband again afterward. In the evening they are back again, and they pray together and they eat together. While they share the prayers and the meals, they also share the rhythm of family life.

The family members also share the blessings. The exchange of blessings and prayers $^{8}$ is possible because all the members have identical blessings and prayers inscribed in their minds. Each member knows that she can say the right blessings at the right moment because of the countless repetitions of the blessings in her life. And she also knows that her fellow members can manage it in the same way. The actual exchange of blessings is to confirm this faith in their fellow family members.

Sharing blessings is identical with sharing meals. While their mouths are consuming the same meal at the same table, their inner senses are tasting the same taste. The taste is not identified by the taste of the food alone. Each person has his/her own taste in food which he/she has developed in his/her habitual life. And each family has its own taste and each people has its own taste. The particular food the family shares stimulates a certain point on the map of taste which is also shared by the family. If you are a member of the family, you know the taste of the particular vegetable soup prepared by a certain member of the family even before you consume the soup, or even before she cooks it in her pan. The acts of consuming the soup with your mouth and tasting the soup with your senses serve to confirm the fact that you are the member of the family.

We may now pay some attention to the pictures attached to these chapters of Geunta. One peculiarity is that the pictures do not necessarily correspond to the contexts of the chapters and they do not have the coherence the stories of these chapters have. In the picture for the chapter "Lunch," there are four people eating lunch in a modern Western-style house. They have nothing to do with the story of the chapter except that they too are eating lunch. In these pictures, Si Ati goes to school in the morning from a traditional house and lulls her baby-sister in a traditional Acehnese-style house, but she recites the letter she has received in front of her family in a modern livingroom, in which a sofa, a table with a flower vase, and a painting hanging on the wall can be seen. Why is this? Perhaps it does not matter. The pictures are there in order to be disregarded.

8. See James Siegel, "Prayer and Play in Atjeh," Indonesia, 1 (April 1966), pp. $1-21$. 
Si Ati's life described in the textbook is not only Si Ati's life, but the life of any Acehnese child. In the morning not only do Si Ati and her brothers and sisters go to school, but all the girls and boys in Aceh go to school with their brothers and sisters. At noon everyone is expected to perform the noon prayer and eat lunch with his/her family at home. Si Ati can be anyone, any girl, regardless of whether she lives in a luxurious new house or a traditional Acehnese house. Anyone can be Si Ati, as long as she shares the rhythm of daily life. Their houses may vary, their family numbers may vary, and their names may vary, but one thing they have in common, which is most important, is that everyone shares the identical rhythm of family life. If you share the rhythm, you would know what others are doing just by looking up at the sky to check the position of the sun. You would know what your friend will do after going home from school even before she leaves the school ground. The very act of going to school with a clean white shirt in the morning is to confirm that she shares the life of Si Ati, she shares the life of anyone who shares the life of Si Ati.

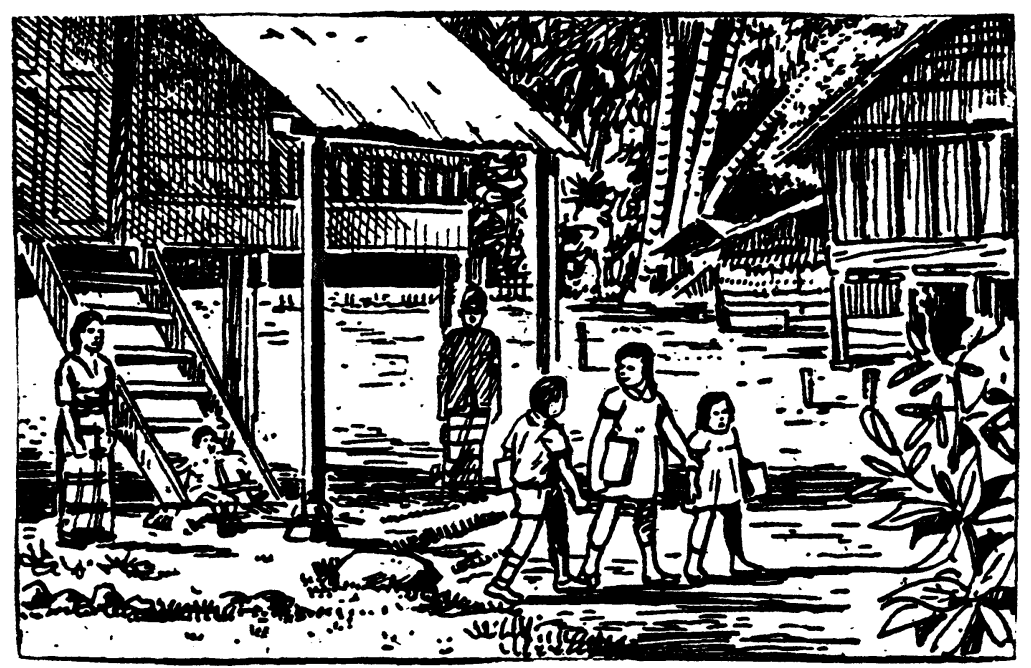

What does this whole business of sharing mean to the young reader? Suppose I am qualified to become the model child, Si Ati, what is to happen to me? In the morning, before I leave for school, I would say "assalamu alaikum." As soon as I say the blessing, my mind begins to type out the return blessing "alaikum salam," and by hearing my parents voicing what is typed out in my mind 1 am to be assured that peace is unto me. But if my mind does not function that way, I am disturbed, which is unfortunate.

I share not only the blessings with Si Ati, however, but the entire span of life. That is, what Si Ati puts in her bag should be identical with what 1 put in my book bag. Therefore my reflection upon the "tah buku" should also be identical with Si Ati's. "In the bags there are various things. Reading books, drawing books, notebooks, pencils, all together." The thought of a comic book 1 could have put in my book bag should not come floating through my mind. If it does, I should be ashamed of myself. If the words "the morning rice" do not recall any such advice, it is not too late for me to imprint Si Ati's reminder in my mind. "You have to eat your morning rice. If not, you get sick." In so doing any other thought is to be deleted. Tomorrow morning I will be just like Si Ati both in my physical activities and in my mind's activities. And I will be assured while reading the chapter on "Going to school" in the classroom. I am also going to tell my brother who sometimes dines out that to do so distracts the rhythm of my family life. It may sound like baking an apple pie by following a recipe for "homemade apple pie" from a cookbook, but the textbook, as the cookbook, provides the model for the rhythm of everyday life. 
There is one more chapter in Geunta Three which we cannot disregard. The plot of this chapter is also based on the story we have read in Batjoet Sapeuë, section 2. Reading. The story is expanded and placed in an entirely new context.

7. Buying eyeglasses

There was a man. The man possessed a small fortune. Spending it was beyond a sweet joy.

His clothes consisted of very good garments. Moreover they were well refined. His shoes were always shining. His jacket and trousers were always clean.

He desired to see the city of Medan [banda Midan]. Then he went to Medan by train.

In the train he found numerous people. It was packed; some stood and some were seated.

When it reached the city of Langsa the train stopped. No sooner had the train come to a halt than a young child got into the train. In his hands were many kinds of newspapers [soerat haba]. The young child sold newspapers in the train.

Nearly all people bought newspapers. Because there was news [ haba baro]. Some also absorbed themselves [peulalè droë] reading the newspapers in the train.

By the will of God those who read the newspapers all had eyeglasses to put on.

Then one person sat next to the man. The person had no eyeglasses. But when he began to read the newspaper he put on eyeglasses.

The person was very absorbed [lalè] in reading the newspapers. Sometimes he laughed and smiled.

Not long after that the train arrived in Medan.

After an interval of two days in the city of Medan, the man went to a store that sold eyeglasses.

At the same time he stopped to buy a newspaper. He wanted to read it after he bought the eyeglasses.

Then he entered the eyeglass store.

He saw many eyeglasses in that store.

"Are there any good eyeglasses?" he asked the storekeeper.

"There are," answered the storekeeper. Then the storekeeper took out two or three pairs of eyeglasses from which to choose.

The man picked up a pair and put them on. Then he read the newspaper. As he could not read it he changed the pair.

Again he picked up a pair. He read the newspaper once more. But he could not read it either.

After tens of pairs of eyeglasses, not even one could make him read the paper. By no means was he able to read the newspaper with these eyeglasses.

Then at last he said to the storekeeper: "Teungku, not a single pair can make me read! How could you ever say your eyeglasses were good?"

As soon as the storekeeper heard this remark, he was much surprised: "Why are these eyeglasses not good?" asked the storekeeper.

"I want to buy eyeglasses with which I can read. But from all these eyeglasses, not a pair could make me read. That is the reason I say they are not good," answered the man.

The storekeeper was even more surprised.

Then he asked: "Are you capable of reading?"

"If I were capable of reading, why should I buy eyeglasses?" 
The first half of the story portrays the uneasiness the man felt when he found himself in the midst of strangers who seemed to share something which he could not share with them.

Perhaps for the first time in his life the man took the train to Medan. Medan is the largest city in Sumatra, located on the East Coast of Sumatra, that is, outside Aceh. At the very moment he got into the coach of the train, he found himself in a strange and unfamiliar dimension. He was inside a box-like space which began to swing when the train started. There were many people in the coach, none of whom he knew.

Now nearly all of the people bought newspapers, and they became absorbed in reading them. The man saw that they were carefree and occupied, in the state of "Ialè," while reading the papers. They were like those babies who were rocked in their cradle-coach while being lulled with a lullaby. The man alone could not hear the lullaby that the others seemed to hear while reading the papers. The people reading the papers looked like a group of confidants who were listening to whispers, sometimes they laughed and sometimes they smiled. The man spent two days in Medan and then went to buy eyeglasses. Obviously during his two-day stay in Medan, he had been no more assimilated into the city's life than he had been in the train.

The other half of the story follows what the man did in order to cast off his uneasiness. He tried tens of pairs of eyeglasses, and somehow in the end the man came out of the store wearing a pair of eyeglasses and holding a newspaper under his arm. This is shown in the picture which is attached to the story. Though we know that he was not yet satisfied with his eyeglasses and he could not understand any of the contents of the paper, his appearance is appropriate for the man, a rich educated youth, walking on the streets of Medan.

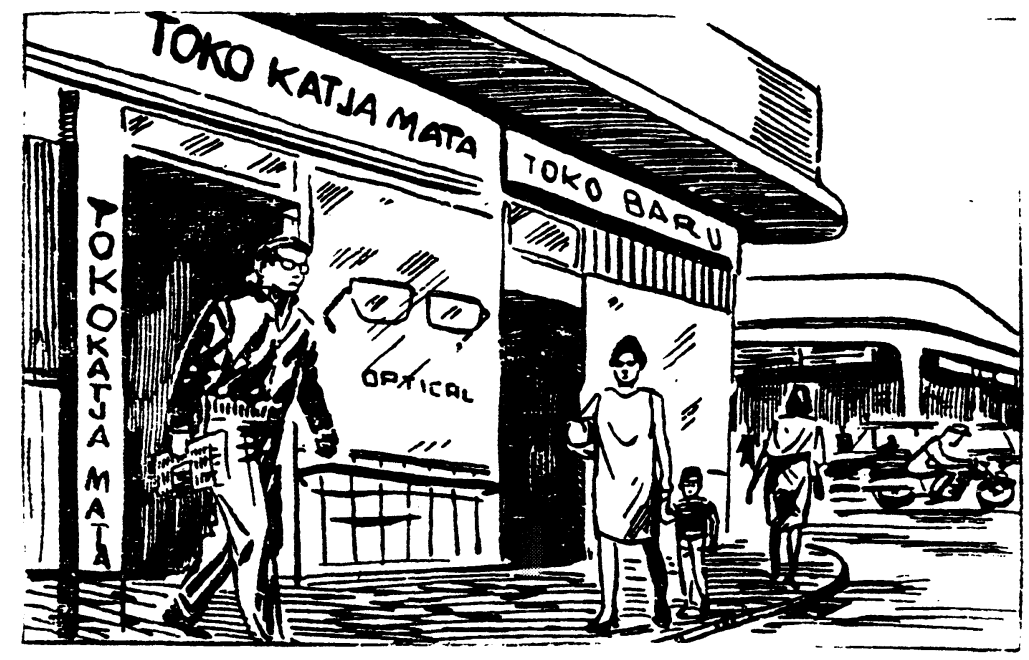

The Geunta story seems to start by asking the question as to the sort of men who could ever have received the Dutch-sponsored education in 1910's Aceh. The young reader of Batjoet Sapeuë must have been the child of a rich family, rich enough to afford all the expense of his schooling. He is after all equivalent to the Geunta story's young man who happened to possess a small fortune. The fortunate youth may well wear good Western garments and shoes, and keep them clean, because he had acquired this knowledge by reading Batjoet Sapeuë at school. But at the same time, he may do this because he has money to buy Western garments and keep them clean always. The knowledge of Western adat can be realized only because he has money to spend for it. 
The destination of this Western-educated rich youth is nowhere but Medan, the center of Dutch colonial economy and culture in Sumatra. Where else can he ever imagine going? The railway connects Aceh to Medan as the path to penetrating Dutch colonial rule. The young man is rich enough to buy a train ticket to Medan, in other words, he is rich enough to buy Western schooling which takes him to the center of the colonial world. The train coach is his classroom. He left his family, his memory, and his previous viewpoint of the world at the train station in order to become a passenger on the train. The man in the midst of strangers feels the same way the young student feels in his classroom while reading Batjoet Sapeuë. $\mathrm{He}$ is lost in his classroom. The village he knew looks different when viewed from the window of the train. That is an abridged view in which he can see the arrangements of the village. Yet he can no longer hear the rooster's crow on the train. He can hear nothing to reassure him. At a loss in the train, being cut off from the village he knew, he is led to feel the need of eyeglasses in order to read the contents of the paper.

The Batioet Sapeuë reader would say "How stupid! What he needs is not eyeglasses but schooling." Yet the Geunta reader would think that what he needs in order to become capable of reading is practice, countless repetition.

According to Geunta, as we have seen, reading consists of two stages. The first stage is the repetition of the texts countless times. In order to carry out repetition one first needs to have an earnest will. While inscribing the texts in one's mind, one needs to be alert and watchful over one's mind, the condition of "hana lalè." Because the control of one's mind as well as the control of one's voice is essential in order not to be distracted by anything else. This learning process is supported by anticipation of the pleasure one will obtain after the completion of learning.

At the next stage, as a result of the previous efforts, one can read the texts fluently with seeming spontaneity, filled with the joy of being swept away in the reverberation of sounds in one's mind. One is allowed to enjoy the luxury of carefree indulgence of oneself, in which one is controlled and occupied by one's mind, the state of lalè. The attention key is released. Yet one's mind is so programmed in the previous stage, that what comes out of one's mind is studied spontaneity. Therefore, while allowing oneself unrestrained gratification, one is able to unify oneself with all the others. All the others who share the same texts inscribed in their minds, all the others who share the reverberation of sounds in their resonating bodies.

These two stages of learning are like embodying the texts in one's mind as a sounding board. The reverberation of sounds one can feel and enjoy is also the confirmation that one can read what one is reading because one has already prepared a sounding board for it in one's mind. Without this sounding board, no matter how sweet the sound may be to one's ears, one cannot enjoy the taste of reverberation in one's inner sense.

The storekeeper's question "Are you capable of reading?" can also be translated as "What are you capable of reading? [Peuë dröëneu jeuët meubaca?]" In other words, what kind of sounding boards has the young man prepared in his mind? Without them he cannot read what he reads. Because he does not feel and understand what he is reading. The young man may be able to read in the sense of Batjoet Sapeue reading. After the expensive schooling from Aceh to Medan, he should be able to divide and name the words and arrange them. Yet mere attendance at school, or the train ride from Aceh to Medan, which can be purchased with money, does not prepare any sounding board in his mind. In the sense of Geunta reading, only earnest effort makes one capable of reading. 
After all, the two questions "Are you capable of reading?" and "What are you capable of reading?" are the same questions. Without understanding what he is reading, how could he read anything? He may spend his money on whichever eyeglasses he desires, but we know that he will never be satisfied by any one of the pairs of eyeglasses. And he will have to keep searching for the eyeglasses which will enable him to read. The man of the Geunta story may be as stupid as the man of the Batjoet Sapeuë story, but this is the man who is the product of Batjoet Sapeuë schooling. This seems to be the answer Geunta tries to present to its readers in this story of eyeglasses.

Thus after studying Geunta, we are now to understand the difference between the young man who bought eyeglasses and the young children who are now reading Geunta. The young readers of Geunta have the rooster's crow imprinted in their mind. They have all the blessings inscribed in their mind before they come to school. They have the lullaby already imprinted in their mind even before they become old enough to attend school. When they read Geunta, therefore, they know what they are reading about. When they learn how to read the textbook, furthermore, they can easily register and reproduce the lines their teacher reads for them. Therefore, they can repeat after their teacher line by line. Because they already know the sounds and the meanings of their language which are imprinted in their mind. Geunta is the textbook of their own language. Geunta tells its readers that the very fact they are now reciting this textbook, Geunta, is confirmation that they share one language, Acehnese. Along with the lullaby, the rhythm of daily life, and the prayers, the blessings, and the taste of vegetable soup. They share what the Acehnese have shared and what the Acehnese will share in the future as well. What they share should not be left behind, should not be discarded and written off. They should rather be cherished. Because without them, Acehnese ceases to exist. The sound without a sounding board can never reverberate.

Geunta we recite with all the will we have,

We keep it to pass on to you, younger brothers and sisters.

If Geunta is never far away,

It is certain all your wishes will be fulfilled.

Be earnest in listening while reciting

The mind which is slow in learning becomes fluent

If you recite with earnest will

Your thoughts will be good, learning will be achieved. 